\title{
Shrinking Gender Barriers, - Sustainable Business Opportunity in Unisex Beauty Salons for Entrepreneurs in Urban India
}

\author{
S. Wagh
}

\begin{abstract}
The paper attempts to explore the potential for entrepreneurial opportunities in Unisex beauty salons in urban India. It also explores the cultural and socio-economic factors creating this unique business domain which attempts to enlarge the space of beauty practices breaking gender barriers. India in particular, presents a paradoxical situation where in one hand, the Unisex Salons are growing craze in metros particularly, among the youth, yet it largely remains a caste-based profession. Hence, it becomes imperative to carry out a study exploring the cultural, socio-economic factors and the stigma that surrounds the beauty salon practices in India today. The shrinking gender spaces which are engendering the places of beauty practices can be seen as reflecting the shift in, the 'people' aspect of sustainability. From secondary data analysis and review of literature it is found that India as an emerging market has potential for entrepreneurship and job creation in the wellness and beauty segment. As beauty is becoming an important discourse of modern lifestyle changing gender identities in the metro cities of India and favorable socio-economic condition are creating unique opportunity which can be explored by females and male entrepreneurs. The unisex salons segment has the potential of creating jobs for beauticians and hairstylist in both organized and unorganized sector.
\end{abstract}

Key words: Cultural factors, Entrepreneurial opportunities, Gender, Socio-economic factors, Unisex Beauty Salons.

\section{INTRODUCTION}

The Indian express first page article on September 8th, 2019 read, "Ahead of Saturday 'mulakaat', inmates' throng Tihar beauty parlour" [1]. The article narrates story of an inmate an under trial who spends her time as an employee at the beauty salon inside the jail. She is very happy that her training as a beautician is fetching her some job and respect even when she is an under trail. The article also reports of how inmates use parlour services to sometime groom themselves. In a nut shell, beauty service inside a prison today, provides a small window of hope for some and secures basic human right to live a dignified life even as an under trial. Beauty is perception driven and cannot be defined precisely.

It has come to become an integral part of human existence and an imminent product of consumption in today's consumer society. However, with time, meaning attached to what is beauty has been changing. Beauty now comes to be recognized as a broader segment titled, 'Beauty and Wellness'. It is no more a hygiene concern but practice of grooming, pampering and even feeling empowered.

Revised Manuscript Received on March 2, 2020.

* Correspondence Author

S. Wagh: Assistant Professor, Symbiosis College of Arts and Commerce. Pune, India. Email: sarika.more@symbiosiscollege.edu.in
Rapid urbanization, media influence, increase in disposal income and easy availability of international beauty brands have increased the demand for beauty and beauty related products and services. For country like India, which is an emerging economy and a young nation any segment, that appeals, to the younger age group is ought to be a sunrise sector expected to fetch the required rise in GDP, employability and entrepreneurship.

According to a report by National Skill Development Council on human resource and skill requirement in beauty and wellness sector along with KPMG (2017) estimates, the market size of global beauty industry to be $\$ 1.4$ trillion and is expected to grow at the CAGR of $15 \%$ annually for next half of the decade [2]. Penning down the potential of Indian beauty and wellness segment is worth appreciating. The Indian beauty and wellness segment is expected to grow at CAGR of $18.6 \%$ which is above the global trend. The Indian beauty salon industry stands alone at INR. 10,000 crores (Smergers report, 2013) [3]. Factors such as increasing purchasing power of India middle class leading to increased spending on lifestyle needs, rap and increasing awareness of grooming among men have led to boost the demand for beauty and grooming services.

The Beauty and wellness segment are classified into four major categories such as Sale of Beauty Products, Fitness and Slimming services and, Rejuvenation and Beauty Salon Services. The salon segment further becomes part of hygiene oriented and image enhancement classification. The services under salon include hair, nail and skin care. The types of salons models found in India are the traditional barber shops which still account for the major portion followed by women beauty parlours and the modern unisex beauty salons which are soon catching up in the metro cities, tier I and tier II cities of India.

The salon segment however, witnesses mainly players from the unorganized sector. The trend however is gradually shifting and is witnessing more players from the organized sector entering Unisex salons. The growth of organized segment is expected to be thirty percent whereas, the unorganized segment is expected to grow at a rate less than twenty percent. With dearth of skilled manpower, higher attrition rate, lack of standardization, lack of funding and challenges in scaling up a non-merchandise service haunts the possibilities of micro, small and medium enterprises to enter this segment. However, the initiatives by the Indian government towards improving the quality of its human resource such as National Skill Development mission, Startup India Stand up India scheme and increased number of world class training institutes 
are some of the steps addressing the issue. The government of India established the Beauty and wellness sector skill council which is the national body federation for the promotion and growth of the beauty and wellness industry. It is indeed a milestone step towards development of the salon segment in the country. The use of our traditional knowledge of Ayurveda and Herbal treatments and ability to convert them into modern day beauty solution under one roof such as Unisex Salons has potential for entrepreneurship development in India.

\section{LITERATURE REVIEW}

According to World Health Organization, Gender is a social construct. It defines characteristics of women and men. It the identity developed, that shapes, the roles and relationships of and between groups [4]. Gender characteristics vary from society to society and from culture to culture. They play a significant role in defining acceptable male and female gender roles and identities. In everyday life, terms gender and sex are used interchangeably. However, their meanings are different. Sex, is a biological orientation however gender, is a learned identity formed through nurturing process. Because, gender in most cases is considered to be binary that is, limited to men and women is the reason why gender and sex are considered to be same at most instances. Businesses tend to use these gender cues to promote their products and services. A study on gender depiction in magazine advertisement by Goffman [5], observes, that the cultural norms, values and ge magazines to carry messages depicting gender roles and identity. Like the famous fairness cream Fair and Lovely creates female identity whereas the macho men who wish to look fair need to use Fair and Handsome. This in fact has created a new narrative of modern lifestyle. Modern living and way of life places a lot of importance to body, beauty and attractiveness [6]. It is quite evident through research that beauty in past has been associated with females or femininity. Research speaks volumes about beauty and beauty practices. For instance, each historical period has had its own culture specific beauty standards [7]. But what draws attention is, beauty is a big business today characterizing large scale production, international distribution networks, marketing and a billion dollars' sales. In a way, the popular culture and modern lifestyle has led to create immense opportunities for beauticians, hairdressers, nail artists and cosmetic companies.

In context to entrepreneurship development, beauty business and emerging economies according to another scholarly work [8], emerging economies are found to be market oriented. That is, the entrepreneurial efforts and ventures are customer driven and oriented towards the emerging needs of the customers. Right from Jawed Habib one of the leading hair and beauty brands in salons segment in India to creation of another popular brand like VLCC have been successful entrepreneurial attempts in the salon segment only because these entrepreneurs adopted market-oriented approach. According to Muntean [9] Entrepreneurs have greater potential of new job creation.

In the opinion of Ndubisi [10], it is entrepreneurs who seek and identify new opportunities for markets and product development. Entrepreneurial activity and economic prosperity are closely connected. Entrepreneurs provide source of income and employment for themselves and for other, produce new and innovative products or services. It has been found that entrepreneurs tend to contribute more in favorable conditions than in economies which lack favorable conditions. Hence, efforts of the government in creating the pull factors of entrepreneurs is essential.

Business and sustainability have become the burning issues of current research discourse. Hence, entrepreneurial attempts in beauty salons business needs a fresh look from sustainability dimension. Researchers like Schaltegger and Wagner [11] who have researched on entrepreneurship and sustainability observe that, entrepreneurs who desire to have sustainable business have generated new services, products and techniques leading to decrease negative impact on environment and enhanced the quality of life.

Gobble [12], describes sustainability as the way of doing business and also as the source of innovation. Sustainability consist of broad range of innovation and social impact. According to Rajasekaran [13], true sustainability is inclusive of innovation which is capable of addressing the businesses and social impact which reshapes the business system. Entrepreneurs are also perceived as individuals who utilize resources, labour, markets and communities to become sustainable [14].

According to Hanson [15], though entrepreneurship is seen as creating employment, boosting exports and increasing tax base but it also conceived that entrepreneurship is a process marked by deep stereotypical gender gaps and identities. This is the reason that while choosing nder relations are used by beauty as business or entrepreneurial venture is perceived as preferred by women and not by men. But, with the creation of popular culture relating to beauty and aesthetics and business opportunities in wellness industry the gap between gender identity of the business and that of the entrepreneur is reducing creating vast opportunities for both gender. It can be argued that beauty salons are not very technology driven and therefore they lack the scope for innovation and entrepreneurship development too. However, Danielle Kost, [16] in article 'What's really disrupting businesses? puts down that essentially, there is a confusion that its technology which is causing disruption hence, business need become tech savvy for survival. Rather, the author finds out that disruption has been read in a wrong way. The observation narrates, that its new comers who are able to simply spot the customers need faster and serve them are the one who cause disruption and not technology in most cases. This phenomenon has been majorly observed in the emerging economies. With respect to India as an emerging economy and urban India in particular, is hub of opportunity for beauty salons. According to $\mathrm{Mc}$ Kinsey report, 2012 on Urban cities their increasing size and power of cities in emerging markets like India, will be witnessing rise in household income more than number of household and individuals in consuming class [17]. From the review of the literature it is evident that the new modern narrative around beauty, gender and entrepreneurship is changing in emerging markets and hence based on this an inquiry should be made leading to the following research questions. 


\section{RESEARCH QUESTIONS}

1. Which socio-economic factors at macro level in India led to emergence of Unisex Beauty Salons?

2. What cultural changes does India presently witness towards gender identities to create new business opportunity particularly in Unisex Beauty Salons?

3. Does Unisex Beauty Salons have the potential for entrepreneurship development?

\section{RESEARCH METHODOLOGY}

The present study is based on secondary data analysis majorly focusing upon the entrepreneurial potential in Unisex Beauty Salons. The researcher has collected data from the reports provided by the National Skill Development and KPMG report titled, Human Resource and skill requirement in the beauty and wellness sector 2013-17 and 2017-2022. Report by FICCI on Future of Wellness Industry Business World, 2018. Also, sources such as National Sample Survey, National skill development center and other scholarly works from JSTOR and Google Scholar. The web articles have also been referred.

\section{SCOPE OF STUDY}

The scope of the present study is limited to understanding entrepreneurial opportunities in Unisex Beauty Salons in Urban agglomerate India. The secondary data used for the purpose has been considered from the financial year 2013 and estimated data up to financial year 2022. The urban agglomerate definition as per All India Census,2011 has been considered which defines urban agglomerate as, continuous urban spreading constituting a town and its adjoining outgrowths [18].

\section{DATA ANALYSIS AND DISCUSSION}

Beauty is a universal experience. It is subjective and a perception driven concept. However, when beauty becomes universal it is obvious that the quest to attain universally acceptable beauty standards gain momentum. Universalization of beauty can be attained only when 'beauty' is democratized through easy access and affordability. Whether developed markets or emerging, beauty has been democratized. No doubt, social places like beauty parlours and salons are witnessing a double-digit growth. Hence, it becomes important to explore socio-economic and cultural aspects shaping new domains of beauty practices in India.

India witnessed a major shift in its economic profile post 1990's economic reforms which, in turn, ushered changes at societal level. As India adopted the new economic policy, it opened doors to international brands and largely to the western cultural practices which were disseminated through media creating new set of demands. Beauty industry was no exception to this. New beauty ideals and body aesthetics products made their way into the Indian households. For example, fairness creams into Indian houses. The new Indian middle class emerged as the new consumer of new global India. It is generally observed, that when people are provided avenues backed by ability to pay, increase in demand is obvious. When per capital incomes doubled and smaller towns transformed rapidly into cities and cities into Metros and Mega cities, in this urban India, beauty became an everyday affair in one's life.

Baghel, Parasarthy and Gupta [19], in their ethnographic study of parlours in Mumbai observed that Mumbai's social life changed drastically post 1990's. With the arrival of new cosmopolitan public, Mumbai witnessed new urban culture. The conspicuous consumption of the Mumbaikar's became the aspiration for all in India.

As India, emerged as, new service economy, beauty practice took a front seat. This new economy expected its employees to look beautiful and body aesthetics came to change the work culture dynamics. Both men and women were expected to look appropriate and beautiful. The dress code culture in workplaces emerges from the new service economy. Hence, the urban India social places such as Beauty Parlours and Salons gained importance. As changes at economy level were realized so were at societal and cultural levels too.

Culture and gender dynamics is another axis on which beauty services needs to be explored. Culturally shaped behavior and attitudes play a significant way in determining one's behavior and choices. In the words of historian Harari pg. [51] [20], 'Ever since the Cognitive Revolution, there hasn't been a single natural way of life for Sapiens. There are only cultural choices, from among a bewildering palette of possibilities.

It is culture, that shapes our perception towards our choices and shapes gender identities too. Indian's conception of beauty is also shaped by the larger macro and micro cultural environment. As such, the new femininity and masculinity also get its definition from the cultural backgrounds.

The gender shift is not just caused due to adoption of standardized globally derived gendered ideas about femininity and masculinity but, it is the socio-economic and cultural changes witnessed through change in lifestyle, occupation and new ideals in urban India that led to reinvent the traditional gender identities. It is because of these new gender identities that no more men are expected only to be macho but also beautiful. It is essentially this gradual change in acceptance of gender identities which led to creation of 'Metrosexual Male identity' which is the new marketing appeal.

The Metrosexual male identity is not anymore only macho but beautiful too. Men are therefore, seen as new potential consumers of beauty products and services [19]. Similarly, another important factor is the cosmopolitan nature of urban cities that men and women are observed to be sharing the work space and other social and public places. The process of urbanization is so that it allows both men and women to participate in the cosmopolitan culture. Increased workforce participation by women is also one of the leading reason making both men and women become comfortable in sharing public space. Emergence of new social place such as Unisex Beauty Salons is an outcome of the shrinking Cosmo urban gender space.

An important factor that led to mediate the cultural and social changes was 'Media'. 
Media has been successful in creating meaning around the concept beauty and successfully percolating it. The representation effects the media is capable of creating was used as tool to form identities about personalities, beliefs, values, attributes [21].

With respect to Indian society and choice of occupation, caste system still plays a dominant role. The hair dressing profession in particular is practiced by Navidar Community and still looked upon as caste-based practice. However, the changing social perception about professions such as hairdressing and salons are moderately diminishing. Also, urban occupational culture that way remains quite open for occupational choices irrespective of caste opening a plethora of opportunities for entrepreneurs is the field of Salons industry. A closer look into the homegrown brand of beauty salons in India such as Juice Salon the first of its kind unisex salon in Delhi, Enrich Unisex Salons from Mumbai are stories of entrepreneurs from non Navidar community and their success stories stand apart from the caste orientation to motivate the potential entrepreneurs.

Exploring the possibilities of entrepreneurial opportunities and job creation in this segment and sustainability the NSDC and KPMG report, 2013-17, 2017-22 makes following broad observations;

- Unisex business model is finding acceptance among the youth.

- Low rental and manpower costs.

- Increased penetration of retail.

- Incremental Human Resource Requirement.

- The workforce among salons are women which is over $50 \%$

- As the economic profile of workforce is witnessing a shift as the mid-income household candidates are picking jobs in this sector.

- Growth of salon is concentrated in top 50 cities of India.

Table I: Beauty Salon segment of India and overview (2013-18)

\begin{tabular}{|c|c|c|l|}
\hline $\begin{array}{c}\text { Salon Sub } \\
\text { segment }\end{array}$ & $\begin{array}{c}\text { Market Size } \\
(\mathbf{2 0 1 3}) \text { in INR }\end{array}$ & $\begin{array}{c}\text { Estimated Growth Rate in } \\
\text { percentage (2013-18) }\end{array}$ & \multicolumn{1}{|c|}{ Fastest growing segment } \\
\hline Skin care & 62 billion & $16 \%$ & Anti- ageing segment \& Fairness cream for men \\
\hline Color & INR 17 Billion & Not Available & Hair color, Nail and Lipstick segment \\
\hline Hair & INR 125 Billion & $30 \%$ to 35\% & Shampoos and Conditioners \\
\hline Personal Care & INR 608 Billion & $20 \%$ & Men grooming \\
\hline
\end{tabular}

Source: Beauty \&Wellness Report, NSDC and KPMG, 2013-2017,2017-22

Table: II Classification of Cities according their Earning Potential and Consumption Potential

\begin{tabular}{|l|l|l|}
\hline $\begin{array}{l}\text { Cities with High earning potential and } \\
\text { high spending potential }\end{array}$ & $\begin{array}{l}\text { Cities with Moderate earning and } \\
\text { high spending potential }\end{array}$ & $\begin{array}{l}\text { Cities with moderate earning and } \\
\text { moderate spending potential }\end{array}$ \\
\hline Delhi & Ludhiana & Patna \\
\hline Kolkata & Amritsar & Indore \\
\hline Ahmedabad & Chandigarh & Bhopal \\
\hline Pune & Faridabad & Surat \\
\hline Greater Mumbai & Kanpur & Vizag \\
\hline Hyderabad & Guwahati & Mysore \\
\hline Chennai & Vadodara & Bhopal \\
\hline & Coimbatore & Raipur \\
\hline & Kochi & \\
\hline
\end{tabular}

Source: Table II and III Beauty and Wellness Report, NSDC and KPMG, 2013-2017,2017-22.

Table III: Dualism in the beauty salon segment.

\begin{tabular}{|l|l|l|l|}
\hline Sector & $\begin{array}{l}\mathbf{2 0 1 3} \\
\text { (Units } \\
\text { in } \\
\text { lakhs) }\end{array}$ & $\begin{array}{l}\mathbf{2 0 1 7} \\
\text { (Units in } \\
\text { lakhs) }\end{array}$ & $\begin{array}{l}\mathbf{2 0 2 2} \text { (in } \\
\text { lakhs) }\end{array}$ \\
\hline $\begin{array}{l}\text { Organized } \\
\text { sector }\end{array}$ & 12 & 24 & 50 \\
\hline $\begin{array}{l}\text { Unorganized } \\
\text { Sector }\end{array}$ & 22 & 38 & 71 \\
\hline
\end{tabular}

Table IV: Incremental Human Resource Requirement.

\begin{tabular}{|l|c|c|c|}
\hline Segment & $\begin{array}{c}\text { Workforce } \\
\text { participatio } \\
\mathbf{n} \text { in 2013 }\end{array}$ & $\begin{array}{c}\text { Workforce } \\
\text { participatio } \\
\mathbf{n} \text { in } \mathbf{2 0 1 7}\end{array}$ & $\begin{array}{c}\text { Workforce } \\
\text { participatio } \\
\mathbf{n} \text { in2022 }\end{array}$ \\
\hline $\begin{array}{l}\text { Beauty } \\
\text { Salons }\end{array}$ & 34 lacs & 62 lacs & 122 lacs \\
\hline
\end{tabular}

Table V: Workforce distribution by function in beauty salon.

\begin{tabular}{|l|c|}
\hline Function & $\begin{array}{l}\text { Workforce distribution in } \\
\text { percentage }\end{array}$ \\
\hline Managerial Staff & $5 \%$ \\
\hline Support Staff & $5 \%$ \\
\hline Hairstylist & $45 \%$ \\
\hline Beauticians & $45 \%$ \\
\hline
\end{tabular}

Source: Table IV and V Beauty and Wellness Report, NSDC and KPMG, 2013-17 and 2017-2022. 
Analysis of the above provided data in NSDC and KPMG report, 2017

- Table III data reflects that the unorganized sector is expected to get larger by taking a jump from 22 lakhs units in 2013 to 38 lakhs in 2017 and to 71 lakhs by 2022. It is expected to grow by $86.8 \%$ between 2017 and 2022. Hence, it is in the unorganized segment where lies a plethora of opportunities for pushing entrepreneurial talents to steadily infuse the shift from unorganized sector to organized sector. As with the growth of the organized sector issues such as creating long term employment benefits can be generated for the larger employed labour force in the Indian Economy. In India the organized sector in the beauty salon industry is expected to touch 50 lakhs units from by 2022.

- The incremental human resource requirement data provided in table IV in the beauty salon segment is also expected to grow in the near future. At all India, it is expected to generate 122 lakhs new jobs by 2022. The sector is in need of roughly 62 lakhs labour participation currently. Beauty and wellness sector skill council of India is an initiative in this direction to create skilled manpower. In the coming year many new players are expected to make their way into the beauty and salon segment. One such imminent example is Lakhme salons who were only into women segment entered the unisex version by launching Lakhme He and She. This trend is expected to increase the human resource requirement in beauty salon segment in particular.

- The workforce distribution by nature of work in beauty salons is positively leaning towards jobs such as Beautician and Hairdresser which stands at $45 \%$ staff requirement in each of the category provided by as per table $\mathbf{V}$. The managerial staff and support staff requirement are 5\% each respectively. With respect to Unisex Salon, India would need more men and women labour force in the two categories such as Beauticians and Hairdressers. This would also help in creating a healthy balance in labour force participation since beauty salons are traditionally considered to be women oriented. The avenue now can be viewed by both genders to be pursued as career.

- The potential of Unisex Salon through entrepreneurial efforts have more opportunities in the Urban India or tier I and tier II cities reflect table II data. If the data of cities across India is to be studied based on their potential to earn income and potential to spend. One can observe, that India, has approximately seven cities as per NSDC KPMG report, 2017 with high propensity to earn and to consume. Cities with moderate capacity to earn and high propensity to consume are nine. These cities can be considered as potential geographic target markets for Unisex Beauty Salons by to be entrepreneurs.

- As per table I data dividing the sector into Skin, Colour, Skin and Personal care it is the Hair segment which alone is expected to increase by 30 to $35 \%$ and which is the one of the fast-growing segments. The Unisex Beauty salons have been observed to have grown in the hair segment peculiarly. The reason being the traditional barber saloons meant for men were getting out of fashion as men started moving to the high-end salons. The Hairdressers who are also in most cases the owners found it easier to shift to Unisex Hair Salons as the skill of hairdresser was still useful plus they were able to give a face lift to their shops. They also now could attract the

younger men consumers. By employing an additional hairdresser for females or learning female hair dressing these micro business ventures are incurring the same cost for both gender and realizing a greater rate of return than previously.

At this stage a reference of successful entrepreneur's attempt in Unisex Salon is worth a mention. Vikram Bhatt coming from non Navidar community is first of its kind entrepreneur who started the Unisex salons in Mumbai. The first-generation entrepreneur Vikram founded Enrich Salons in 1997 and has today grown to chain of 50 salons across different metros in India. Enrich like the other salon is capitalizing on the smaller ticket capacity of Indians and desire for comfort and luxury. Similarly, Jawed Habib Hair Expresso which is a Unisex hair salon is perfect example of small ticket size being utilized by offering haircuts in just Rs. 199 to Rs.499. According to Forbes magazine 2016 the Jawed Habib's Hair and Beauty business is worth $\$ 30$ million. It has 870 salons in 24 states across 110 cities with approximately 15,00,000 customers to its credit in India and he is the third-generation entrepreneur in this business [22]. Both these stories and many other like this are unique for changing the Indian narratives for entrepreneurship in Unisex salon business.

\section{CONCLUSION AND FUTURE SCOPE}

Body aesthetics and beauty, plays a dominant role in modern consumer society. Emerging nations in particular, are witnessing the same which in turn, is dramatically changing its lifestyle narratives and beauty discourse. New engendering spaces such as creation of Unisex salon practices, are fast catching up the urban social space generating entrepreneurial opportunities for both women and men. The cultural shifts and socio-economic factors such as shaping of new gender identities.

The new service economy has led to create the Cosmo culture in which men and women are comfortable in sharing their beauty practice place creating new domains Unisex salons.

It has also created metrosexual male identity where is men are not expected to be Macho but beautiful and presentable. As these new gender identities get carved and barriers of strict gender defined identities reduce the new Indian urban Cosmo culture gives way to new businesses.

Increasing spending capacity, rapid urbanization and reduced caste based professional choice in beauty salon business are leading to create opportunities for entrepreneurs in India. The unisex salon business is expected to grow with growing urbanization.

Traditionally perceived women ventures are now providing opportunities for men too. To be entrepreneurs, can explore the Unisex hair version as a beginning as it needs less investment in terms of capital and human resource. They can capitalize on small ticket size of small-town consumers. The need is to train the hands and nurture the entrepreneurial spirit. Beauty practices are age old and will sustain in future. The fortune lies in exploring the entrepreneurial efforts in spotting the trends and fast serving it by adopting market orientation strategy. 
The unisex version of salons can be further explored not just from male and female gender point of view but also from the third gender point of view. It also has further scope for scholarly works from the view of service provider and the gender roles.

\section{REFERENCES}

1. Somay Lakhani, 'Ahead of Saturday 'mulakaat', inmates' throng Tihar Beauty Parlour', Indian Express, September 8, 2019.

2. Report Human Resource and skill requirement in the beauty and wellnesssector.https://nsdcindia.org/sites/default/files/Beauty-Wellness.p df

3. Smergersreport,https://www.smergers.com/businesses/beauty-and-welln ess-businesses-for-sale-and-investment-opportunities-in-pune/s603/c9/t0/

4. World Health organization on Health and gender available https://www.who.int/health-topics/gender

5. Goffman, E. Gender advertisements New York: Harper \& Row 1976

6. Giddens, Anthony. Modernity and Self-identity: Self and Society in the Late Modern Age. Stanford, CA: Stanford UP, 1991

7. Kenneth Lipartito, "Culture and the Practice of Business History", Business and Economic History, 1995.pp 1-41.

8. Garry D. Bruton and David Ahlstrom Krzysztof Obloj, Entrepreneurship in Emerging Economies: Where Are We Today and Where Should the Research Go in the Future Research Gate Page"1-15.

9. Muntean, S. C. Embracing entrepreneurship. Indiana Business Review 2011 Vol 86(1).

10. Ndubisi, N. O. Entrepreneurship and service innovation. Journal of Business \& Industrial Marketing, 2014 Vol 29, 449-453.

11. Schaltegger, S., \& Wagner, M. Sustainable entrepreneurship and sustainability innovation: categories and interactions. Business Strategy and the Environment, 2011, Vol 20, pp.222-237.

12. Gobble, M. M. Innovation and sustainability. Research Technology Management, 2012, Vol 55(5), pp. 64-66.

13. Rajasekaran, B. Sustainable entrepreneurship: past researchers and future directions. Journal of Entrepreneurship and Management, 2013. 2(1), pp.20-27

14. Chrysostom, E. The success factors of necessity immigrant entrepreneurs: In search of a model. Thunderbird International Business Review, 2010 Vol 52, pp.137-152.

15. Hanson, S. Changing Places through Women's Entrepreneurship. Economic Geography, 2009 Vol 85(3), pp.245-267.

16. Danielle Kost, HBR working knowledge for Business leaders, retrieved from

https://hbswk.hbs.edu/item/what-s-really-disrupting-business-it-s-not-tec hnology

17. McKinsey report, on Urban world rise of the consuming class report https://www.mckinsey.com/ /media/McKinsey/Featured\%20Insights/Ur banization/Urban $\% 20$ world $\% 20$ Cities $\% 20$ and $\% 20$ the $\% 20$ rise $\% 20$ of $\%$ 20the $\% 20$ consuming\%20class/MGI_Urban_world_Rise_of_the_consu ming_class_Full_report.ashx

18. Census report, 2011 retrieved http://censusindia.gov.in/2011-provresults/paper2/data_files/India2/1.\% 20Data\%20Highlight.pdfhttps://www.forbes.com/sites/ranisingh/2016/0 6/30/jawed-habib-the-hair-stylist-with-a-30-million-salon-empire/\#473e $33 \mathrm{~d} 44 \mathrm{~b}$

19. Deepmala Baghel, D. Parthasarathy \& M. Gupta (Will you walk into my parlor? Spaces and practices of beauty in Mumbai, South Asian Popular Culture, 2014 Vol 12:3, pp.163-179.

20. Yuval Noah Harari, Sapines A Brief History of Humankind. Vintage Book London. Random House, UK. ISBN 9780099590088. Pg.51

21. Graeme Burton, Media and Society critical perspective. Rawat Publication Second Edition, 2010, ISBN 978-81-316-0888-3.

22. ForbesIndiahttps://www.forbes.com/sites/ranisingh/2016/06/30/jawed-h abib-the-hair-stylist-with-a-30-million-salon-empire/\#2d6598f14bf7

\section{AUTHORS PROFILE}

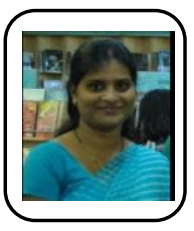

Mrs. Sarika Wagh, received her Bachelor degree and Master's degree in Commerce from Savitribai Phule Pune University, India in the subject of Advanced Accountancy and Taxation. She is pursuing Ph.D. in marketing from Savitribai Phule Pune University. The area of research is Customer satisfaction and Unisex Beauty Salons. Currently teaching at Symbiosis College of Arts and Commerce, Pune as Assistant Professor. Holds a teaching experience of ten years in subjects such as Entrepreneurship, Marketing and Accountancy. The researcher has conducted workshops for exchange program students from Canada, Germany and Japan. She has also visited KEDGE BUSINESS SCHOOL IN FRANCE for a teaching assignment in 2016 November -December. Her research work consists of 3 published articles in the areas of Social Ventures and Women, Corporate Social Responsibility with Public Private Partnership and Inclusive Development and Education. The research article on Social venture women is available on google scholar. 